\title{
O impacto da cultura organizacional no desempenho financeiro das empresas da região norte de Portugal
}

O entendimento da cultura organizacional é um elemento fundamental na gestão, considerando as constantes mudanças do ambiente organizacional e a necessidade de adaptação interna e integração externa das organizações. Este artigo tem por objetivo estudar se a cultura organizacional influencia o desempenho financeiro das organizações, bem como o impacto de acordo com a cultura predominante. A cultura organizacional é avaliada a partir do Organizational Culture Assessment Instrument, desenvolvido por Cameron e Quinn (2006), com seis dimensões - características dominantes, liderança organizacional, gestão de colaboradores, espírito de grupo, ênfases estratégicas e critérios de sucesso - e, deste enquadramento resultam quatro culturas: clã, adocrática, de mercado e hierárquica. Em termos metodológicos, através de um inquérito por questionário identifica-se o tipo de cultura predominante nas empresas da região Norte de Portugal e, para estudar as relações entre a cultura organizacional e o desempenho financeiro, recorre-se à análise de correlação e de regressão múltipla. Os resultados sugerem a existência de relações de pequena intensidade entre os tipos de cultura analisados (adocrática, de mercado e hierárquica) e o desempenho financeiro das empresas daquela região. Verifica-se um efeito positivo da cultura adocrática e de mercado no resultado líquido e um efeito negativo da cultura hierárquica, mas os resultados não evidenciam diferenças significativas no desempenho financeiro das empresas com culturas organizacionais distintas.

Palavras-chave: Cultura Organizacional; Desempenho; Desempenho Financeiro.

\section{The impact of organizational culture on the financial performance in enterprises from north region of Portugal}

\begin{abstract}
Understanding the organizational culture is a key element in the management considering the ever-changing organizational environment and the need to adapt internal and external integration by organizations. This article aims to study the influence of organizational culture on the financial performance of organizations and the impact according to the prevailing culture. In terms of methodology, through a questionnaire survey following Cameron and Quinn (2006), with six key characteristics - dominant characteristics, organizational leadership, management of employees, organization glue, strategic emphases and criteria of success - it is identified the predominant culture in enterprises Portugal North Region. To study the relationship between organizational culture and financial performance, make use of the correlation and multiple regression analysis. The results suggest the existence of small intensity of relations between the analyzed types of culture (adhocracy, market and hierarchical) and the financial performance of the companies in that region. It is verified a positive effect of adhocracy culture and market on net profits and a negative effect of hierarchical culture.
\end{abstract}

Keywords: Organizational Culture; Performance; Financial Performance.

Topic: Recursos Humanos

Reviewed anonymously in the process of blind peer.

\section{Flávia Araújo}

Escola Superior de Estudos Industriais e de Gestão, Portugal flaviarc.araujo@gmail.com

\section{Maria da Conceição de Castro Sousa Nunes}

Escola Superior de Estudos Industriais e de Gestão, Portugal mariacastro@eseig.ipp.pt

Fernanda Amélia Ferreira

Escola Superior de Estudos Industriais e de Gestão, Portugal fernandaamelia@eseig.ipp.pt

DOI: 10.6008/SPC2179-684X.2016.003.0004
Received: 10/06/2016

Approved: 14/11/2016
Referencing this:

ARAÚJO, F.; NUNES, M. C. C. S.; FERREIRA, F. A.. O impacto da cultura organizacional no desempenho financeiro das empresas da região norte de Portugal. Revista Brasileira de Administração Científica, v.7, n.3, p.52-64, 2016. DOI: http://doi.org/10.6008/SPC2179684X.2016.002.0004 


\section{INTRODUÇÃO}

Ao longo dos tempos, as organizações têm vindo a deparar-se com dificuldades resultantes da instabilidade e do clima de incerteza que paira sobre as diferentes culturas e países por todo o mundo. Esta realidade adversa, sentida pelos diversos tecidos empresariais, induziu investigadores para a procura das causas explicativas do grau de desempenho empresarial. De facto, o desempenho parece ser uma das principais preocupações por parte das empresas, com particular destaque para a orientação para os resultados e desempenho financeiro que permitam garantir a sustentabilidade. Alguma da literatura sobre esta temática procura identificar variáveis que possam influenciar e explicar, positiva ou negativamente, o desempenho financeiro das organizações, permitindo dessa forma obter respostas concretas no sentido de poder corrigir e melhorar esse mesmo desempenho. Uma das variáveis causais que vem sendo apresentada na literatura, de diversas formas, por vários autores, é a cultura organizacional (PETERS e WATERMAN, 1982; OGBONNA e HARIS, 2000; MACHADO, 2001; CAMERON e QUINN, 2006; ZHENG, YANG e MCLEAN, 2010; DUKE II e EDET, 2012; YESIL e KAYA, 2013) que poderá constituir um elemento diferenciador das organizações, contribuindo para o seu desempenho. Alguns autores (DENISON, 1984; GORDON, 1985; BARNEY, 1986; SANTOS, 1998; SILVA, 2008; ZHANG e ZHU, 2012; YESIL e KAYA, 2013), estudaram a relação entre cultura e desempenho de forma a compreender como o desempenho depende da cultura.

O objetivo deste artigo é o de avaliar o impacto da cultura organizacional no desempenho financeiro das empresas da região Norte, a mais industrializada de Portugal, onde predominam as microempresas. Este artigo está organizado da seguinte forma: no ponto 2 faz-se uma revisão da literatura em torno do conceito de cultura organizacional e de desempenho, bem como de estudos que abordam a relação entre estes dois conceitos, aplicados ao contexto empresarial. No ponto 3 apresentam-se as hipóteses em estudo e, de seguida (ponto 4) descreve-se a metodologia. Após a caracterização da amostra (ponto 5), apresenta-se o modelo a estimar e analisam-se os resultados obtidos para a região do Norte de Portugal (ponto 6). Por último, no ponto 7, apresentam-se as conclusões.

\section{REVISÃO TEÓRICA}

\section{Cultura Organizacional}

O conceito de cultura organizacional tem sido muito debatido na literatura económica. No entender de Lee e Yu (2004), a cultura organizacional é um conjunto de normas e valores dos membros da organização, enquanto para Pettigrew (1979) é um sistema de significados coletivamente aceites por um grupo num determinado momento. Schein (1985) refere que a cultura é o padrão criado pelos indivíduos que agem num coletivo, afirmando ainda que cultura organizacional é um conjunto de pressupostos básicos que um grupo inventa, desenvolve e/ou descobre de forma a aprender a cooperar com os problemas de integração interna e de adaptação externa (SCHEIN, 1990). Para Smircich (1983) cultura é um conjunto normativo que mobiliza uma organização e expressa os valores ou ideais sociais e crenças partilhadas pelos membros que a compõe. De acordo com Peters e Waterman (1982) a cultura organizacional desempenha um papel crucial na 
determinação do sucesso e eficácia das entidades. Pode, igualmente, ser uma fonte de vantagem competitiva sustentável, se essa cultura for valiosa, rara e difícil de imitar (BARNEY, 1986) e representar um dos ativoschave das organizações (ZHENG, YANG e MCLEAN, 2010).

Muitas formas têm sido sugeridas ao longo dos anos resultantes da identificação de várias dimensões que permitem caracterizar a cultura organizacional. Schein, em 1984, defende que a força e a congruência representam as dimensões culturais mais relevantes, enquanto que para Deal e Kennedy (1983) essas dimensões seriam a velocidade do feedback e o grau de risco. Martin (1992), defende o consenso e integração cultural, diferenciação e conflito, e fragmentação e ambiguidade, e Hofstede (2001) foca-se em quatro dimensões-chave: a distância ao poder, o individualismo, a masculinade, e o grau de aversão à incerteza.

Agregando várias dimensões sugeridas na literatura, Cameron e Quin (2006) desenvolvem uma ferramenta que permite avaliar as dimensões-chave da cultura organizacional e desenvolver, nos casos em que tal se demonstre necessário, uma estratégia de mudança com o intuito de potenciar as vantagens competitivas da empresa, muito utilizada na literatura económica (FEKETE e BOCSKEI, 2011; YESIL e KAYA, 2013, entre outros). Apesar da diversidade de tipologias de cultura organizacional encontradas na literatura, este artigo centra-se na desenvolvida por Cameron e Quinn (2006), que foi utilizada por diversos autores (FEKETE e BOCSKEI, 2011; YESIL e KAYA, 2013).

O modelo desenvolvido por Cameron e Quinn (2006), com o objetivo de clarificar e avaliar de forma coerente a cultura organizacional, assenta em três dimensões contrastantes. Uma delas, denominada de flexibilidade e controlo, centra-se nas questões relacionadas com a estrutura organizacional, ajudando a compreender se existe uma orientação para a estabilidade, para a estrutura burocrática, focando-se assim num controlo, ou para a inovação, para uma estrutura mais informal, sendo assim mais orientada para a flexibilidade. A dimensão seguinte, interno e externo, debruça-se sobre o facto de a entidade estar preocupada com o desenvolvimento individual, valorizando a estabilidade na estrutura de trabalho ou se, em contrário, se encontra preocupada com o alcance dos seus objetivos e com a própria competitividade. Por fim, a dimensão dos meios e fins foca-se numa divisão ou ao nível dos processos, por exemplo a produtividade e o lucro, ou dos resultados, como por exemplo o planeamento e a definição de objetivos. Estas dimensões dão origem a um modelo que permite avaliar a cultura organizacional, definindo quatro tipos de cultura: clã, adocrática, hierárquica e de mercado.

De acordo com Cameron e Quinn (2006), a cultura clã assenta nos valores familiares (empresa familiar), caracterizando-se pela visão partilhada quanto aos valores, objetivos, coesão, participação, individualismo e sensação de grupo. Alguns aspetos característicos desta dimensão são o trabalho em grupo, a partilha de conhecimentos, a integração e união dos trabalhadores, assim como a participação na organização e a existência de um compromisso com aqueles que contribuem para a realização do trabalho. As assunções básicas deste tipo de cultura passam por um ambiente de trabalho gerido numa lógica de união/equipa, onde o desenvolvimento dos empregados e dos clientes não é visto apenas como uma fonte de lucro mas também como uma forma de desenvolver sustentavelmente parcerias e relacionamentos. Em 
suma, o ambiente da empresa é visto como sendo mais "humano" já que valoriza as relações e sentimentos, atribuindo aos funcionários uma maior responsabilização e confiança o que potência a participação e lealdade.

Relativamente à cultura adocrática, que melhor caracteriza o século XXI de acordo com Cameron e Quinn (2006), assenta no pressuposto de que as iniciativas pioneiras e a inovação conduzem ao sucesso, algo que deve ser tido em consideração para a criação dos novos produtos e serviços para o futuro, e na qual o grande objetivo da gestão é incentivar e maximizar o empreendedorismo e a criatividade. Estas características são apresentadas como impulsionadoras de novos recursos e mais resultados/lucros, daí a ênfase na visão do futuro, na anarquia e numa imaginação de certa forma disciplinada. Este tipo de cultura promove a mudança e tem como objetivos aumentar a capacidade de adaptação, a flexibilidade, a criatividade, já que a incerteza, a ambiguidade e o excesso de informação são típicos.

A cultura hierárquica é definida a partir do trabalho de Max Weber, que procurou dar resposta a um problema que assolou as empresas no virar do século XX e que se baseava no desenvolvimento, ao nível da produção, de produtos e serviços. Este tipo de cultura rege-se com base em procedimentos que orientam/governam as pessoas, onde as preocupações a longo prazo são a estabilidade e a eficiência. A cultura hierárquica caracteriza-se por um lugar formalizado e com uma estrutura bem delineada para trabalhar.

A cultura de mercado, que começou a ser conhecida nos finais dos anos 60, atingiu o seu auge através de trabalhos desenvolvidos por Williamson (1975) e Ouchi (1981), entre outros, nas décadas de 70/80 (CAMERON e QUINN, 2006). Este conceito não deve ser confundido com a orientação das empresas para o mercado, nem com o marketing em si. O verdadeiro significado desta cultura é que a própria empresa é vista como um mercado, sendo gerida por normas semelhantes às que regem este, ou seja, uma entidade que adota este tipo de cultura está essencialmente focada no ambiente externo em detrimento do ambiente interno à própria organização, concentrando-se nas transações com os seus fornecedores, clientes e parceiros. Ao contrário da cultura hierárquica, onde o controlo interno é gerido por regras, especialização de tarefas e decisões centralizadas, a cultura de mercado opera principalmente através de mecanismos de mercado, como por exemplo a fidelização de clientes e orientação para os resultados. A condução de transações é o principal foco desta cultura, de forma a criar vantagens competitivas e os objetivos são maximizar os resultados "bottom line", a força nos nichos de mercado e alargamento de targets. Os valores principais são a competitividade, a produtividade, a eficiência e a eficácia de forma a melhorar a performance (YESIL e KAYA, 2013).

\section{Desempenho Organizacional}

O paradigma mundial evoluiu ao longo dos últimos anos, originando que mais variáveis, e não somente o desempenho financeiro, como no tempo da Era Industrial, passasse a desempenhar um papel fundamental. Assim, como o conceito de cultura organizacional, pela sua subjetividade, é entendido de 
diversas formas por vários autores, a temática do desempenho tem sido bastante debatida (BARNEY, 1986; ILGEN e SCHENEIDER, 1991; CAMPBELL e OUTROS, 1993; PATON, 2003; DUKE II e EDET, 2012).

Barney (1986) apresenta dois conceitos distintos para desempenho. O primeiro diz respeito à comparação entre o valor que uma organização gera, usando os seus ativos, com o valor que os proprietários desses ativos esperam receber. Já o segundo conceito baseia-se numa visão de múltiplas partes interessadas, ou seja, o desempenho é medido conforme a percepção de cada stakeholder sobre a organização. Esse conceito gera, portanto, diferentes percepções de desempenho, cada uma destas com os fatores que, subjetivamente, considera mais importante. Ilgen e Scheneider (1991) defendem que o desempenho não pode ser definido por uma ação em si, mas sim por um processo de análise crítica e de avaliação. Esta definição vai de encontro ao que é defendido por Campbell e outros (1993) que referem que apenas as ações que podem ser classificadas e medidas, podem ser relacionadas com desempenho. Para Paton (2003) desempenho representa o que determinadas pessoas da gestão, envolvidas na organização, definem e acordam entre si, implícita ou explicitamente, enquanto para Kaplan e Norton (1996) desempenho é atingir determinados objetivos, atribuídos a um responsável, balanceando e alinhando os mesmos com a estratégia da organização, de forma a permitir alcançar determinadas expectativas.

\section{Estudos Empíricos que Relacionam Cultura Organizacional e Desempenho}

A nível empírico vários autores estudaram a relação entre cultura organizacional e desempenho. Santos (1998) efetuou um estudo para explorar o impacto da cultura organizacional no desempenho das empresas, utilizando dados de treze empresas brasileiras do setor têxtil. $O$ autor conclui que a cultura estaria significativamente associada ao desempenho, e que as empresas com culturas fortes apresentavam melhor desempenho. Ogbonna e Haris (2000) estudaram a relação entre cultura organizacional e desempenho, incluindo o estilo de liderança como a terceira variável do modelo, numa amostra de trezentas e vinte e duas empresas de vários setores de atividade económica do Reino Unido. Os resultados evidenciaram que as quatro variáveis de medição da cultura organizacional estão associadas, de alguma forma, à performance organizacional, demonstrando uma relação positiva entre o tipo de cultura competitiva e inovadora e uma relação negativa entre o tipo comunitária e burocrática. Sorensen (2002) estudou a relação entre culturas fortes e a variação do desempenho organizacional, defendendo que essa relação está dependente do modo como as culturas fortes afetam a aprendizagem organizacional, de acordo com as mudanças internas e externas. Os resultados indicaram que nas empresas de cultura forte o desempenho foi menos variável em ambientes estáveis, sendo que em ambientes voláteis os benefícios de uma cultura forte desaparecem.

Silva (2008) estudou a relação entre a cultura organizacional e o desempenho econômico-financeiro através da realização de um estudo às 20 maiores empresas do Estado do Espírito Santo, no Brasil. A autora conclui que existe evidência que a cultura organizacional não está significativamente associada ao desempenho econômico-financeiro e refere que os resultados estatísticos apresentam limitações, pois as variáveis não são muito adequadas para se obter um modelo explicativo do desempenho. Duréndez e Garcia (2010) investigaram a relação entre cultura organizacional, sistemas de controlo de gestão e desempenho. A 
amostra utilizada para este estudo é composta por oitenta e nove Pequenas e Médias Empresas (PME). De acordo com os resultados a cultura predominante é a clã, e a adocrática é a cultura menos relevante. Os autores concluem que a cultura inovadora (junção do clã e adocrática) e os sistemas de controlo de gestão têm efeitos positivos sobre o desempenho. Fekete e Bocskei (2011) estudaram o impacto da cultura organizacional no desempenho das empresas. Para o efeito, o estudo debruçou-se sobre duzentas e cinquenta e seis empresas da Hungria. Embora os resultados evidenciem efeitos de reduzida dimensão da cultura organizacional sobre as variáveis financeiras, o mesmo não acontece para outras dimensões do desempenho organizacional. Não obstante, a cultura hierárquica tem um efeito negativo no desempenho financeiro, enquanto o mesmo é holístico para as culturas adocrática, clã e de mercado, em particular estas duas últimas. De igual forma, a cultura hierárquica influencia negativamente o desempenho empresarial na perspetiva dos clientes e dos processos operacionais, enquanto a clã e a de mercado têm efeitos positivos, concluindo que a cultura clã é a que tem efeitos positivos de maior relevo em todas as dimensões analisadas do desempenho, ou seja, desempenho financeiro e não financeiro. Zhang e Zhu (2012) realizaram um estudo para avaliar o efeito dos quatro tipos de cultura de Cameron e Quinn (2006) no desempenho financeiro e de mercado das empresas. $O$ estudo foi aplicado a vinte e cinco empresas. Os autores concluíram que a cultura adocrática e a cultura de mercado têm um impacto positivo no desempenho financeiro e de mercado, enquanto as culturas clã e hierárquica têm um impacto negativo. Mais recentemente, Yesil e Kaya (2013) estudaram o efeito da cultura organizacional na performance financeira das empresas tendo, para o efeito, utilizando informações de trezentas empresas da Turquia. Apesar de algumas limitações do estudo, reconhecidas pelos autores, não há evidência estatística de que a cultura (clã, adocrática, mercado e hierárquica) tenha influência no desempenho financeiro.

Salienta-se que existem estudos, como o de Yesil e Kaya (2013), que referem que a cultura organizacional poderá ter um impacto indireto no desempenho através da conversão e gestão do conhecimento e inovação.

\section{METODOLOGIA}

O presente estudo é baseado num modelo em que a cultura organizacional é a variável independente e o desempenho financeiro é a variável dependente. Em consonância com o modelo temos a seguinte hipótese: $\mathrm{H}_{1}$ : A cultura organizacional influência o desempenho financeiro das empresas. Esta hipótese, proposta a partir das contribuições teóricas e empíricas apresentadas, procura avaliar a existência de uma relação entre a cultura organizacional e o desempenho financeiro das empresas.

Para avaliar a existência, ou não, de uma relação entre a cultura organizacional e o desempenho financeiro das empresas, recorreu-se a uma amostra do tipo probabilística composta por empresas da região Norte de Portugal.

Foram selecionadas aleatoriamente 380 empresas daquela região às quais foi enviado um inquérito por questionário via Lime Survey. A população alvo foram os gestores de topo. Das 380 empresas obtiveramse 127 respostas, das quais 66 foram consideradas válidas. Deste modo a taxa de resposta obtida foi de 
$33,42 \%$, ainda que apenas $51,97 \%$ destas últimas pudessem ser utilizadas neste estudo, por erros ou omissões encontradas. Aplicou-se, numa primeira fase, o inquérito por questionário desenvolvido por Cameron e Quinn (2006), para identificar o tipo de cultura predominante nas empresas desta região. Posteriormente, efetuaram-se testes de correlação entre a cultura organizacional e o desempenho financeiro e, para averiguar a hipótese da cultura influenciar o desempenho financeiro, a especificação do modelo recai, tal como Silva (2008) e Yesil e Kaya (2013), no modelo de regressão linear múltipla.O tratamento de dados foi realizado através da ferramenta estatística Statistical Package for the Social Sciences (SPSS) que permitiu a realização de uma análise univariada, testes de correlação e estimação dos parâmetros do modelo de regressão linear múltipla.

O inquérito por questionário encontra-se dividido em quatro secções. A secção "perfil" representa as características dos respondentes, nomeadamente no que diz respeito ao género, idade, nível de escolaridade, função que desempenha na organização e antiguidade na empresa. Na secção "caracterização do negócio" averigua-se algumas características deste, a saber: ano de criação, número de colaboradores, setor da atividade em que está inserido e a forma jurídica da organização. A terceira secção está inteiramente relacionada com a caracterização da cultura organizacional, sendo que as questões elaboradas resultam de uma adaptação realizada ao modelo desenvolvido por Cameron e Quinn (2006), como instrumento de diagnóstico da cultura organizacional. Este instrumento assenta numa metodologia que tem por base a elaboração de questionários individuais, com seis dimensões da cultura organizacional - características dominantes, liderança organizacional, gestão de colaboradores, espírito de grupo, ênfases estratégicas e critérios de sucesso -, em que cada dimensão é representada por quatro questões, cada uma delas relacionada com cada tipo de cultura - adocrática, hierárquica, clã e de mercado. Para avaliar o conjunto dos 24 itens (4 por dimensão), foi utilizada a escala de resposta de tipo Likert de cinco pontos. Para identificar a cultura predominante das empresas foi calculada a pontuação média obtida em cada uma das seis dimensões relativa a cada tipo de cultura organizacional.

A última secção do inquérito por questionário fornece os indicadores financeiros em estudo, tendo sido escolhidos como indicadores o ativo, o resultado líquido do exercício e o crescimento anual das vendas, tornando-se possível, através do conjunto dos mesmos, avaliar a sensibilidade destes à variável cultura organizacional.

\section{Caracterização da Amostra}

Observa-se, a partir da Tabela 1, que 30,3\% das respostas utilizadas foram dadas por pessoas do género feminino e $69,7 \%$ do género masculino. Relativamente à idade dos respondentes, agrupada em seis escalões etários, o valor mais elevado obtido incide sobre indivíduos com idade entre os 35-44 anos (47,0\%), seguindo-se, com uma percentagem de $24,2 \%$, os indivíduos com idades compreendidas entre os 25 e os 34 anos, $18,2 \%$ com idade entre os $45-54$ anos, 7,6\% com idade entre os 55-64 anos, e por fim com apenas 1,5\% cada um, os indivíduos com menos de 25 anos e com mais de 65 anos. Os respondentes têm, na sua maioria, formação académica superior: licenciatura $(60,6 \%)$, mestrado $(12,1 \%)$, ou doutoramento (3\%). Com 
formação académica inferior ao ensino superior, observam-se apenas 10,6\% com ensino secundário, 3\% com o 2 ㅇ ciclo do ensino básico e 1,5\% com o 3o ciclo do ensino básico.

Tabela 1: Caracterização da amostra.

\begin{tabular}{|c|c|c|}
\hline DESCRIÇÃO & CRITÉRIO & FREQUÊNCIA RELATIVA \\
\hline \multicolumn{3}{|l|}{ Perfil dos respondentes } \\
\hline \multirow[t]{2}{*}{ Género } & Feminino & $30,30 \%$ \\
\hline & Masculino & $69,70 \%$ \\
\hline \multirow[t]{6}{*}{ Idade } & $<25$ anos & $1,50 \%$ \\
\hline & $25-34$ anos & $24,20 \%$ \\
\hline & $35-44$ anos & $47,00 \%$ \\
\hline & $45-54$ anos & $18,20 \%$ \\
\hline & $55-64$ anos & $7,60 \%$ \\
\hline & $>65$ anos & $1,50 \%$ \\
\hline \multirow[t]{8}{*}{ Formação académica } & Doutoramento & $3,00 \%$ \\
\hline & Mestrado & $12,10 \%$ \\
\hline & Licenciatura & $60,60 \%$ \\
\hline & Bacharelato & $7,60 \%$ \\
\hline & Ensino secundário & $10,60 \%$ \\
\hline & 3ㅇ ciclo ensino básico & $1,50 \%$ \\
\hline & 20 ciclo ensino básico & $3,00 \%$ \\
\hline & Nível 4 & $1,50 \%$ \\
\hline \multirow[t]{5}{*}{ Número de anos na empresa } & $01-05$ anos & $28,80 \%$ \\
\hline & $06-10$ anos & $22,70 \%$ \\
\hline & $11-15$ anos & $18,20 \%$ \\
\hline & $16-20$ anos & $9,10 \%$ \\
\hline & $>20$ anos & $21,20 \%$ \\
\hline \multirow[t]{4}{*}{ Funções que desempenha na empresa } & Gestor & $39,40 \%$ \\
\hline & Diretor & $25,80 \%$ \\
\hline & Operário & $9,10 \%$ \\
\hline & Outras & $25,80 \%$ \\
\hline \multicolumn{3}{|l|}{ Caracterização do negócio } \\
\hline \multirow[t]{4}{*}{ Dimensão } & Microempresas & $30,30 \%$ \\
\hline & Pequenas Empresas & $36,40 \%$ \\
\hline & Médias Empresas & $21,20 \%$ \\
\hline & Grandes Empresas & $12,10 \%$ \\
\hline \multirow[t]{7}{*}{ Forma jurídica } & Sociedade Anónima & $39,40 \%$ \\
\hline & Sociedade por Quotas & $45,50 \%$ \\
\hline & Unipessoal & $9,10 \%$ \\
\hline & Pessoa Coletiva de Utilidade Pública & $1,50 \%$ \\
\hline & Administração Local & $1,50 \%$ \\
\hline & Fundação & $1,50 \%$ \\
\hline & Instituição Particular de Solidariedade Social & $1,50 \%$ \\
\hline
\end{tabular}

No que respeita ao número de anos de antiguidade na organização constata-se que $28,8 \%$ estão na empresa há cerca de 1-5 anos, 22,7\% entre 6-10 anos, há mais de 20 anos correspondem $21,2 \%$, no escalão 11-15 anos com 18,2\% e, por último, 16-20 anos que representam 9,1\%. Assim, verifica-se que grande parte dos respondentes trabalhavam há mais de 5 anos na empresa.

Relativamente às funções que cada indivíduo desempenha na organização é de destacar a função de gestor que representa $39,4 \%$ dos respondentes, seguida da de diretor com $25,8 \%$, assim como "outras" que incluem funções de técnico oficial de contas, administrativo, escriturário, etc. O número médio de colaboradores das empresas em estudo é de 213.

A maior parte das empresas encontra-se dentro da classificação de pequenas empresas $(36,4 \%)$, sendo a segunda posição ocupada pelas microempresas com 30,3\%, seguida pelas médias empresas com $21,2 \%$, e por fim as grandes empresas com $12,1 \%$. 
Considerando a classificação relacionada com a forma jurídica da empresa, verifica-se que as duas formas mais observadas são a constituição sob a forma de sociedade por quotas $(45,5 \%)$ e de sociedade anónima (39,4\%). Constituídas sob a forma de sociedade unipessoal constam apenas 9,1\%, e as outras quatro formas apresentadas (pessoa coletiva de utilidade pública, administração local, fundação, instituição social de solidariedade social) representam cada uma apenas 1,5\%, em relação ao total da amostra.

Relativamente aos indicadores financeiros (2), constata-se que o crescimento anual das vendas apresenta uma mediana de 5,10\% e o resultado líquido do exercício uma mediana de 16.751,50 euros.

Tabela 2: Estatísticas descritivas das variáveis financeiras, 2012.

\begin{tabular}{|l|l|l|l|}
\hline VARIÁVEIS & MÉDIA & MEDIANA & DESVIO PADRÃO \\
\hline Crescimento anual das vendas (em \%) & 17,14 & 5,1 & 69,196 \\
\hline Resultado Líquido do Exercício (em euros) & $3.817 .224,80$ & $16.751,50$ & $20.801 .520,88$ \\
\hline
\end{tabular}

No que respeita às variáveis culturais (culturas clã, adocrática, hierárquica e de mercado) pode verificar-se, pela Tabela 3 , que a cultura predominante é a clã $(3,68)$, seguida da cultura de mercado $(3,57)$, da hierárquica $(3,50)$ e, por último, a cultura adocrática $(3,47)$.

Tabela 3: Estatísticas descritivas das variáveis culturais.

\begin{tabular}{|l|l|l|}
\hline & MÉDIA & DESVIO PADRÃO \\
\hline Cultura Clã & 3,679 & 1,000 \\
\hline Cultura Adocrática & 3,467 & 0,881 \\
\hline Cultura Mercado & 3,566 & 0,9731 \\
\hline Cultura Hierárquica & 3,500 & 0,788 \\
\hline
\end{tabular}

\section{Apresentação do Modelo}

Para verificação da hipótese do estudo, foram extraídos os coeficientes de correlação e aplicou-se o modelo de regressão linear múltipla. O modelo de regressão múltipla pode ser representado pela eq. [1]. Por uma questão de ajustamento dos dados foi usado o modelo Log-linear, já que este fornece coeficientes de regressão geralmente interpretados como a variação percentual na variável dependente para cada aumento de uma unidade na variável independente.

$$
\log (\mathrm{DF})=\beta_{0}+\sum_{\mathrm{i}=1}^{4} \beta_{\mathrm{i}} C_{\mathrm{i}}+\sum_{\mathrm{i}=5}^{7} \beta_{\mathrm{i}} Z_{\mathrm{i}}+\varepsilon
$$

A variável dependente Desempenho Financeiro (DF) é avaliada pelo Resultado Líquido (RL) ou Crescimento Anual das Vendas. As variáveis independentes $C_{\mathrm{i}}$ são variáveis qualitativas ordinais e representam cada um dos tipos de cultura organizacional (clã, adocrática, mercado e hierárquica). $\mathrm{Z}_{\mathrm{i}}$ representam as variáveis de controlo (ramo de atividade económica, forma jurídica e número de colaboradores).

\section{RESULTADOS}

Os resultados da estimação do modelo de regressão múltipla representado pela eq. [1], quando se utilizou o crescimento anual de vendas como indicador do desempenho financeiro das organizações, sugerem a não existência de correlação com as variáveis de cultura; acresce que a capacidade explicativa do 
modelo era fraca, pelo que, se apresentam apenas os resultados para a variável resultado líquido. As variáveis de controlo - ramo de atividade económica e forma jurídica - reduziam a capacidade explicativa do modelo, pelo que não se apresentam os resultados.

De forma a calcular apenas logaritmos de valores positivos foi adicionado o valor $421.002 €$ à variável resultado líquido do exercício, que corresponde ao valor absoluto do resultado líquido do exercício mais baixo da amostra, que denominaremos de resultado líquido ajustado ( $R L$ ajustado), passando o modelo a estimar a ser dado pela eq. [2]:

$\log (\mathrm{RL}$ ajustado $)=\beta_{0}+\beta_{1}$ Clã $+\beta_{2}$ Adocrática $+\beta_{3}$ Mercado $+\beta_{4}$ Hierárquica $+\beta_{5}$ Número de colaboradores $+\varepsilon$

No que se refere aos graus de correlação entre o resultado líquido ajustado e os diferentes tipos de cultura constata-se que são fracos e não são estatisticamente significativos (Tabela 4). Conforme foi possível verificar, o grau de correlação entre a cultura de mercado e o resultado líquido ajustado é de 0,243 sendo considerado baixo, seguido do grau evidenciado entre a cultura adocrática e o resultado líquido ajustado ($0,133)$ muito baixo. Existe, no entanto, um grau de correlação moderado, e estatisticamente significativo, entre o número de colaboradores e o resultado líquido ajustado $(0,474)$.

Tabela 4: Matriz de correlação de Pearson.

\begin{tabular}{lccccc}
\hline & $\begin{array}{c}\text { CULTURA } \\
\text { CLÃ }\end{array}$ & $\begin{array}{c}\text { CULTURA } \\
\text { MERCADO }\end{array}$ & $\begin{array}{c}\text { CULTURA } \\
\text { ADOCRÁTICA }\end{array}$ & $\begin{array}{c}\text { CULTURA } \\
\text { HIERÁRQUICA }\end{array}$ & $\begin{array}{c}\text { NÚMERO DE } \\
\text { COLABORADORES }\end{array}$ \\
\hline Resultado Líquido & $-0,074$ & 0,243 & $-0,133$ & $-0,049$ & $0,474^{* *}$ \\
Ajustado & & $-0,767^{* *}$ & $-0,021$ & $-0,579^{* *}$ & $-0,177$ \\
Cultura Clã & & $-0,184$ & 0,170 & $0,257^{*}$ \\
Cultura Mercado & & & & $-0,515^{* *}$ & $-0,186$ \\
Cultura Adocrática & & & & & 0,118 \\
Cultura Hierárquica & & & & & \\
\hline
\end{tabular}

** Correlação é significativa para um nível de 0,01.

* Correlação é significativa para um nível de 0,05.

Para verificação da hipótese do estudo aplicou-se o modelo de regressão linear múltipla. Foram testadas várias interações entre as variáveis e validados os pressupostos da RLM. Na equação de regressão permaneceram quatro variáveis preditoras positivamente ou negativamente associadas ao resultado líquido: $\log (\mathrm{R} L$ ajustado $)=\beta_{0}+\beta_{1}$ Adocrática $+\beta_{2}$ Mercado $+\beta_{3}$ Hierárquica $+\beta_{4}$ Número de colaboradores $+\varepsilon$ (3) Os resultados da estimação da eq. (3) apresentam-se na Tabela 5.

Tabela 5: Resultados da regressão linear múltipla.

Variável dependente: log (Resultado Líquido ajustado)

\begin{tabular}{|l|l|l|l|l|}
\hline VARIÁVEIS INDEPENDENTES & COEFICIENTES NÃO PADRONIZADOS ( $\boldsymbol{\beta})$ & t & Valor - $\boldsymbol{p}$ & FIV \\
\hline Constante & 13,014 & 3,625 & 0,001 & \\
\hline Cultura Adocrática & 0,745 & 0,333 & 0,741 & 1,412 \\
\hline Cultura Mercado & 1,144 & 0,799 & 0,427 & 1,103 \\
\hline Cultura Hierárquica & $-1,902$ & $-1,167$ & 0,248 & 1,383 \\
\hline Número de colaboradores & 0,001 & 4,002 & 0,000 & 1,090 \\
\hline $\mathrm{R}^{2}$ ajustado & 0.199 & & & \\
\hline F & 0.001 & & & \\
\hline
\end{tabular}

O resultado sugere que $19,9 \%$ da variação total do resultado líquido ajustado é explicada pela relação entre as variáveis independentes (cultura adocrática, cultura mercado, cultura hierárquica e o número de colaboradores). Este valor não difere muito do obtido por Silva (2008), e em outros estudos da mesma 
natureza é ainda mais reduzido (por exemplo, YESIL e KAYA, 2013). Apesar de não ser muito elevado, uma vez que as variáveis explicativas apenas explicam cerca de $20 \%$ da variação do resultado líquido ajustado, não se tem a pretensão de predizer com exatidão aquela variação, mas sim compreender se as variáveis culturais são relevantes para o desempenho financeiro e avaliar a sua importância relativa. É de salientar que existem outras variáveis, que não culturais, que contribuem para a explicação do desempenho.

É importante verificar se as variáveis têm significância para o modelo, para isso procedeu-se ao teste da razão $F$ que apresenta um valor-p inferior a 0,05 , pelo que se conclui que pelo menos um $\beta$ é diferente de 0. Um pressuposto estatístico exigido, passível de ser analisado, é a não existência de multicolinearidade sendo que, para o efeito, verificou-se se os valores dos Fatores de Inflação da Variância (FIV) são inferiores a 10 (pois este é o limite habitualmente considerado para o qual não existe multicolinearidade (PESTANA e GAGEIRO, 2008)), pelo que se pode concluir o pressuposto exigido.

Os resultados do teste t sugerem que o número de colaboradores é estatisticamente significativo, e que as variáveis culturais não são estatisticamente significativas para o modelo, pois para as culturas analisadas o valor-p é superior a 0,05 (adocrática 0,741; mercado 0,427; hierárquica 0,248), indiciando que não há diferenças no desempenho financeiro das empresas do Norte de Portugal analisadas com culturas organizacionais distintas.

\section{CONCLUSÕES}

O mundo empresarial é bastante complexo e competitivo e por isso é crucial que as organizações acompanhem a tendência de evolução, tentando compreender quais as variáveis que podem interferir, positiva ou negativamente, com o desempenho das mesmas. Devido a esta conjugação de fatores, procurouse desenvolver um estudo focado na investigação do impacto da cultura organizacional no desempenho financeiro das empresas. Para concretizar o mesmo foi essencial a utilização do instrumento denominado OCAI, desenvolvido por Cameron e Quinn (2006), que permitiu o diagnóstico da cultura organizacional das organizações, através da caracterização da organização com base em quatro tipos distintos de cultura, sendo elas a cultura clã, a cultura adocrática, a cultura hierárquica e a cultura de mercado.

Para avaliar a relação entre os diferentes tipos de cultura e o resultado líquido foram efetuados testes de correlação e estimação de um modelo de regressão linear múltipla. Os resultados sugerem que, para as culturas organizacionais consideradas, não existe uma relação entre o tipo de cultura organizacional utilizada pela empresa e o desempenho financeiro. Apesar dos coeficientes estimados das culturas adocrática e de mercado (assim como o do número de trabalhadores) serem positivos, sugerindo que o tipo de cultura adocrática como predominante - que dê ênfase à criatividade, à inovação, ao empreendedorismo, que se adapte à mudança, - potencialmente terá uma influência positiva no desempenho da organização, assim como a predominância de uma cultura de mercado - que se centre na competitividade, produtividade, eficiência e lucro - também potenciará esta influência positiva, não se rejeita a hipótese dos coeficientes referidos serem nulos. Os resultados sugerem, igualmente, que a cultura de mercado tem um impacto positivo mais forte sobre o resultado líquido ajustado do que a cultura adocrática. Ao contrário destas, e 
apesar da não significância do coeficiente estimado, uma organização em que predomine a cultura hierárquica - que se foque na autoridade, nas regras e procedimentos na disciplina e que se feche à mudança - potenciará uma influência negativa no seu desempenho. Para analisar se as culturas e o número de trabalhadores explicam o modelo formulado, foi efetuada uma regressão linear múltipla que sugeriu que as variáveis cultura "adocrática", "de mercado" e "hierárquica", assim como o "número de colaboradores", conseguem explicar cerca de $20 \%$ da variação do resultado líquido ajustado. De referir que pode ser considerado natural ter obtido um valor baixo para o coeficiente de determinação, em virtude de existirem outros fatores relevantes na explicação do resultado líquido para além da cultura e do número de colaboradores.

Os resultados deste estudo sugerem a não existência de evidência estatística que suporte a hipótese que a cultura organizacional tenha impacto no desempenho financeiro, avaliado pelos resultados líquidos, das empresas da região Norte de Portugal. Notamos que estes resultados vão ao encontro aos obtidos por Silva (2008) e Yesil e Kaya (2013). Posto isto, não rejeitamos a hipótese de que a cultura organizacional não influencia o desempenho financeiro das empresas.

É de ressalvar que existem estudos, como o de Yesil e Kaya (2013), que referem que a cultura organizacional pode ter um impacto indireto no desempenho através de outras variáveis como a conversão e gestão do conhecimento e a inovação.

É necessário salientar que os resultados deste estudo poderão não estar totalmente ajustados, devido às limitações que apresenta, nomeadamente o facto de o desempenho financeiro ser apenas mensurado pelo resultado líquido, a amostra não ter uma dimensão superior, e o número de respondentes de microempresas ter sido reduzido e não terem sido consideradas outras variáveis no estudo que poderiam influenciar/explicar o desempenho financeiro das empresas.

Em desenvolvimentos futuros sobre variáveis que possam influenciar o desempenho, será interessante incluir outros indicadores que permitam mensurar o desempenho financeiro. Será também de alguma forma interessante incluir outros tipos de cultura e tentar compreender e analisar qual o impacto indireto que a cultura poderá ter nas organizações, e através de que variáveis a mesma exerce esse impacto, como já alguns autores referiram. Torna-se importante, igualmente, explorar outros métodos, nomeadamente o método de análise de trajetórias, permitindo separar os efeitos diretos e indiretos da cultura organizacional no desempenho financeiro.

\section{REFERÊNCIAS}

BARNEY, J. B.. Organizational Culture: Can It Be a Source of Sustained Competitive Advantage?. The Academy of Management Review, v.11, n.3, p.656-665, 1986

CAMERON, K.; QUINN, R.. Diagnosing and Changing Organizational Culture Based on the Competing Values Framework. 2 ed. São Francisco: Jossey Bass, 2006.
CAMPBELL, J. P.; MCCLOY, R. A.; OPPLER, S. H.; SAGER, C. E.. A theory of performance. In: SCHMIDT, N.; BORMAN, W. C.. Personnal Selection. Nova lorque: Jossey-Bass, 1993.

DEAL, T.; KENNEDY, A.. Culture: a new look through old lenses. Journal of Applied Behavioral Science, v.19, n.4, p.498-505, 1983.

DENISON, D.. Bringing Corporate Culture to the Bottom Line. Organizational Dynamics, v.13, n.2, p.4-22, 1984. 
DURÉNDEZ, A.; GARCIA, D.. Innovative Culture, Management Control Systems and Performance in young SME's. In: BONNET, V. A.; GARCÍA, D.. The entrepreneurial society how to fill the gap between knowledge and innovation. Cheltenham: Edward Elgar Publishing, 2010. p.123-125

DUKE II, J.; EDET, G. H.. Organizational Culture as a Determinant of Non-Governmental Organization Performance: Primer Evidence from Nigeria. International Business and Management, v.4, n.1, p.66-75, 2012.

FEKETE, H.; BOCSKEI, E.. Cultural Waves in Company Performance. Research Journal of Economics Business and ICT, Universaty of Pannonia, v.3, n.1, p.38-42, 2011.

GORDON, G. G.. The relationship of corporate culture to industry sector and corporate performance. In: KILMANN, R. H.; SAXTON, M. J.; SERPA, R.. Gaining control of the corporate culture. São Francisco: Jossey Bass, 1985.

HOFSTEDE, G.. Culture's Consequences: Comparing Values, Behaviors, Institutions and Organizations Across Nations. 2 ed. Thousand Oaks: Sage Publications, 2001.

ILGEN, D.; SCHNEIDER, J.. Performance measurement: A multi-discipline view. International review of industrial and organizational psychology. In: COOPER, C. L.; ROBERTSON, I. T.. Chichster: Wiley, 1991. p.71-108

KAPLAN, R.; NORTON, D.. The Balanced Scorecard: translating Strategy into action. Library of Congress, Harvard College, 1996.

LEE, S. K.; YU, K.. Corporate Culture and Organizational Performance. Journal of Managerial Psychology, v.19, n.4, p.340-359, 2004

MACHADO, M.. A Influência da Cultura Empresarial na Produtividade das Organizações. Dissertação (Mestrado em Comportamento Organizacional) - Instituto Universitário de Ciências Psicológicas, Sociais e da Vida, Lisboa, 2001.

MARTIN, J.. Cultures in Organizations. Nova lorque: Oxford University Press, 1992.

OGBONNA, E.; HARRIS, L.. Leadership Style, Organizational Culture and Performance: Empirical Evidence from UK Companies. International Journal of Human Resources Management, v.11, n.4, p.766-788, 2000.

OUCHI, W. G.. Theory Z: How American Business Can Meet the Japanese Challenge. Boston: Addison-Wesley, 1981.

PATON, R.. Managing and Measuring Social Enterprises. Londres: Sage Publications, 2003.
PESTANA, M. H.; GAGEIRO, J. N.. Análise de Dados para Ciências Sociais: A Complementaridade do SPSS. 5 ed. Lisboa: Sílabo, 2008.

PETERS, T.; WATERMAN JR, R.. In Search of Excellence: Lessons from America's best - Run Companies. Londres: Harper Collins Publishers, 1982.

PETTIGREW, A. M.. On Studying Organizational Cultures. Administrative Science Quarterly, v.24, n.4, p.570-581, 1979.

SANTOS, N.. Cultura e desempenho organizacional: um estudo empírico em empresas brasileiras do setor têxtil. Revista de Administração Contemporânea, v.2, n.1, p.47-66, 1998.

SCHEIN, E. H.. Coming to a New Awareness of Organizational Culture. Sloan Management Review, v.25, n.2, p.3-16, 1984.

SCHEIN, E. H.. Organizational Culture and Leadership. São Francisco: Jossey Bass, 1985

SCHEIN, E. H.. Organizational culture. American Psychologist, v.45, n.2, p.109-119, 1990

SILVA, J. B.. Tipos de cultura organizacional e desempenho económico-financeiro: um estudo nas maiores empresas do Estado do Espírito Santo. Dissertação (Mestrado em Ciências Contábeis) - Fundação Instituto Capixaba de Pesquisas em Contabilidade, Vitória, 2008.

SMIRCICH, L.. Concepts of Culture and Organizational Analysis. Administrative Science Quarterly, v.28, n.3, p.339358, 1983.

SORENSEN, J. B.. The Strength of Corporate Culture and the Reliability of Firm Performance. Administrative Science Quarterly, v.47, n.1, p.70-91, 2002

WILLIAMSON, O.. Markets and Hierarchies, Analysis and Antitrust Implications: A Study in the Economics of Internal Organization. New York: Free Press, 1975.

YESIL, S.; KAYA, A.. The Effect of Organizational Culture on Firm Financial Performance: Evidence from a Developing Country. Procedia - Social and Behavioral Sciences, v.81, n.28, p.428-437, 2013

ZHANG, Z.; ZHU, X.. Empirical Analysis of the Relationship between Organizational Culture and Organizational Performance. CONFERÊNCIA NACIONAL DE TECNOLOGIAS DA INFORMAÇÃO E CIÊNCIAS COMPUTACIONAIS. Anais. 2012.

ZHENG, W.; YANG, B.; MCLEAN, G. N.. Linking Organizational Culture, Structure, Strategy and Organizational Effectiveness: Mediating Role Of Knowledge Management. Journal of Business Research, v.63, n.7, p.763-771, 2010. 